\title{
The Geophysics of Northern Ireland: the Tellus Effect
}

\author{
The geophysics of Northern Ireland has recently been redefined by the Tellus \\ airborne geophysical survey, which acquired modern magnetic, radiometric and \\ active frequency-domain electromagnetic data at high resolution. David \\ Beamish $^{1^{*}}$ and Mike Young ${ }^{2}$ describe what this redefinition entails in terms of \\ scientific and other Tellus Effect outcomes.
}

1* dbe@bgs.ac.uk, corresponding author

2 mike.young@detini.gov.uk

In the UK, prior to the onset of revised high-resolution airborne surveying in the late 1990's, the national onshore magnetic data set comprised 430,238 line-km acquired in the late 1950's and early 1960's. These data were acquired at wide flight-line separations of between 2 and $10 \mathrm{~km}$ (tie-lines) and at an elevation of about 1000 feet, and with a previous generation of fluxgate magnetometers.

Northern Ireland was the first part of the UK to conduct an independent cost-benefit analysis and recognise the benefits of modern, high-resolution aerogeophysical surveying. The Tellus project was conceived as a Resource and Environmental Survey for the benefit of both public and private development sectors. The project also included detailed geochemical sampling surveys of soils and streams. These datasets are being used both to promote mineral exploration and to provide environmental baselines that support government planning in economic and sustainable development, social infrastructure, environment and health. The three main geophysical measurements (magnetic, radiometric and electromagnetic) contribute to different aspects of these broad objectives.

A major Tellus concept and effect (the naming itself was significant), was the apportioning of a significant part of the project budget to public awareness, outreach and understanding of science. A very obvious and prolonged low-level airborne survey is an ideal platform for a public outreach campaign, which proved highly effective. Tellus, and the fact that it was about 'Understanding Underground', provided a bridge of understanding between science and everyday culture in the local population and it continues to do so.

\section{The Tellus surveys of 2005 and 2006}

The survey was conducted over a two year period by the Joint Airborne geoscience Capability (JAC) and covered the geopolitical landmass of Northern Ireland, an area of $14,160 \mathrm{~km}^{2}$. Flight lines were extended about $2 \mathrm{~km}$, both over the coast and into the Republic of Ireland. The lines were spaced at intervals of $200 \mathrm{~m}$ and orientated at $345^{\circ}$, on the basis of geological trends. The nominal flight height was $56 \mathrm{~m}$, rising to $200 \mathrm{~m}$ over populated areas. Line lengths of about $50 \mathrm{~km}$ were considered optimum in terms of this specific systematic mapping programme.

The survey area was divided into eight survey blocks labelled A to E2 (Figure 1). The two frequency EM system used in 2005 (3125 and $14368 \mathrm{~Hz}$ ) was replaced by a new four frequency system during 2006 (912, 3005, 11962 and $24510 \mathrm{~Hz}$ ). The survey acquired 81,703 line-km, together with test data sets and tie-lines (Blocks A and B only) to evaluate magnetic levelling procedures. 


\section{The old and the new}

Existing aeromagnetic data (1959/60) across a 20 x $30 \mathrm{~km}$ area (rectangle 1, Fig. 1) centred on a Carboniferous basin in the west are shown in Figure 2a. Fault lines are overlaid largely to aid spatial location. The equivalent Tellus survey data are compared in Figure 2b. Clearly the reduced flight line spacing (by a factor of 10), the much lower flight altitude (a factor of 5 decrease), and the use of modern Caesium magnetic sensors, produce new insights into structural associations. Large scale variations are obviously reflected in both data sets but the extensive dyke swarms, their trends and offsets, very evident in the new data, were quite unresolved by the vintage data. Also evident in the new data are large numbers of 'pimple anomalies' that represent cultural perturbations (many are individual farm buildings with metal structures/roofs). Removing these (magnetic deculturing) has been a major challenge but has been achieved largely by correlation with postcodes to identify locations of potential cultural interference.

The Tellus magnetic data, transformed to a pseudo-gravity field (to emphasise longerwavelength features) are shown in Figure 3. In the northeast the Antrim Lava Group is the largest onshore remnant of the North Atlantic Igneous Province (NAIP) in the UK and Ireland. The lavas show distinct geophysical responses in all three geophysical data sets. As can be seen in Figure 3, their complex, high-wavenumber features dominate the magnetic response.

Magnetic anomalies associated with dyke swarms are prominent and widespread; their numbers and full regional scale extent had previously gone unrecognised. The high resolution magnetic data have allowed identification of four chronologically distinct dyke swarms. This, in turn, has enabled a reappraisal of the Alpine collisional tectonics and Icelandic mantle plume magmatism in the Palaeogene. This large scale revision of the NAIP forms part of the Tellus discovery effect.

Other major large scale magnetic features include the large positive response in the southwest (high susceptibility early Palaeozoic basement rocks beneath the thick Carboniferous cover) and the very pronounced circular positive anomaly associated with the Palaeogene Slieve Gullion Igneous Complex in the south. The observed spatial form is highly appropriate in representing what is essentially the root of a deep seated volcano.

\section{The new}

The Tellus project also provided 256-channel radiometric data sampled at $1 \mathrm{~Hz}(\sim 70 \mathrm{~m})$ and two and four-frequency EM conductivity data sampled at $4 \mathrm{~Hz}(\sim 15 \mathrm{~m})$. The radiometric spectra are processed to provide the three main geological responses due to natural occurrences of Potassium, Thorium and Uranium. The majority of the signal arises from within the upper $30 \mathrm{~cm}$ so soil associations and bedrock derived contributions may be studied. The EM data are processed to provide information on the electrical conductivity distribution from the near-surface to depths in excess of $100 \mathrm{~m}$ (a function of the frequencies acquired).

These two new data sets provide a wealth of broad and local scale information whose full impact continues to be realised. Figure 4 shows the complete radiometric data expressed as a Ternary colour image $($ Red $=$ Potassium, Green $=$ Thorium and Blue=Uranium $)$ with a data set that is cut to the coast and to the central water body (Lough Neagh) to avoid colour bias from the null responses. These are retained (black=no radiometric response) in the water bodies and drowned drumlin features of Fermanagh in the west. At the scale shown, some broad geological associations are evident. The pervasive Antrim lavas display a low radiometric signal but subtle topographic and mineralogical associations can be discerned. 
The bright spot to the northeast of Lough Neagh represents the Tardree rhyolite complex. The boundary of the Antrim lavas is extremely well defined by the attenuated response and confirms a largely bedrock characteristic across the range of soil profiles. The Palaeozoic Southern Upland-Down-Longford (SUDL) terrane in the southeast provides some of the highest energies in all 3 elements. Colour rescaling is required to examine the information in detail. The imaging shown does demonstrate the different radiogenic characteristic of the southern-most tract (the Hawick Group) and the Caledonian Newry Igneous Complex. The granitic Mourne Mountains Complex also stands out in white (where all three elements are high) and turquoise (where Uranium and Thorium are high relative to Potassium).

In detail the radiometric data display many associations with topography, drainage and superficial geology. The redistribution of material during the last glacial period can also be discerned in some localities. When the data are examined in relation to soil type, it is clear that much of the lowest radiometric signals (the darkest areas) are due to attenuation by peat (caused by water content). As peat soils are a significant store of carbon, integrating radiometric and soil survey data has the potential to improve our estimates of soil organic carbon. A case example is provided later. This is a further example of the Tellus effect, one that makes use of new baseline data to explore significant new avenues of research.

The conductivity model obtained at $3 \mathrm{kHz}$ is shown in Figure 5. These data form the most cohesive and extensive mapping of conductivity information across the UK. At this frequency, the data possess a maximum sensitivity to formations in the upper $60 \mathrm{~m}$. The shaded-relief colour plot has been designed to show the most resistive areas in grey, the more conductive areas in blue/yellow and the most conductive features in red. Strong conductivity gradients with obvious geological associations are evident, particularly across formations in the west. The most pervasive high conductivity values are associated with the concealed Lough Neagh basin. The spatial form is complex as is the association with mapped geological units. The conductive zones extend across both Upper and Lower basalt formations and the later Lough Neagh Group sediments. A large number of regional scale, fault-related responses are evident. Many of these are observed only as subtle low amplitude variations detected in the gradient of the response (i.e. discernable only in the shaded response). It should also be noted that that the image contains the quasi-linear and highly conductive response of the major cross-country power distribution grid. Of interest is the Carboniferous limestone terrane in the southwest which exhibits highly variable and distinctive conductivity variations. These data form the first significant assessment of the conductivity of the UK Carboniferous and there is much further work to be attempted in unraveling the characteristics observed in this karst area with groundwater potential. Thus a further feature of the Tellus effect lies in the provision of new geophysical baseline data across some significant formations of UK geology.

\section{The detail}

Much of the Tellus effect lies in the detailed provision of high resolution geoscience information that takes us directly to a case-specific, site scale. An example is taken from the $4 \times 4 \mathrm{~km}$ rectangle (rectangle 2, Fig. 1). The area lies within the Antrim Lava Group. The 3 $\mathrm{kHz}$ conductivity data are shown, overlaid on a topographic map, in Figure 6a. The conductive response of a dual, cross-country powerline route is evident. A regional scale background lithology change is detected by the E-W transition from resistive values in the east to more conductive values in the west. The transition is likely to be due to changes in porosity and/or mineralogy. The corresponding magnetic data (reduced-to-pole) are plotted as an equal-area colour plot in Figure 6b. This shows that the transition in conductivity is also marked by a N-S magnetic feature separating two of the larger compartments within the basalts. Figure 6a also reveals at least four localised high conductivity zones that can each be 
studied further. An inner 1x1 km area defining the location of the active (though then about to close) Ballymacvea landfill is shown in both images. The magnetic anomaly associated with the landfill consists of two adjacent small positive anomalies. The $3 \mathrm{kHz}$ conductivity anomaly extends to the road in the northeast that services the landfill. Using all four frequencies of the EM data it is possible to provide a subsurface conductivity model of the landfill. The resulting 3D conductivity model across the $1 \times 1 \mathrm{~km}$ area is shown in Figure 7. The view shows the distribution of conductivity with values above $60 \mathrm{mS}$ beneath a transparent surface photographic image (the main landfill site lies adjacent to the road). The vertical scale is $30 \mathrm{~m}$. The high conductivity values are vertically compact, extending to a base level of $\sim 15 \mathrm{~m}$. Assuming that the high conductivity values reflect leachate then these conductive pore-fluids are detected to a considerable distance to the west. In other landfills, studied in more detail, the leachate plume direction normally follows that of the hydrogeological gradient.

As the example demonstrates, a very conservative estimate of the number of conductivity anomalies within the Tellus conductivity data set would be 1 per $4 \mathrm{~km}^{2}$. This implies that a minimum of $\sim 3,500$ local scale investigations may be required to fully assess the information content. A further feature of the Tellus effect lies in the amount of local-scale environmental information that is potentially significant.

As noted previously, in detail the radiometric data display associations with topography (drainage), soil type/classification and superficial geology. Figure 8 provides a case study from a 10x10 km area of high ground in the northeast of the survey (rectangle 3, Fig. 1). Figure 8a shows the superficial deposits with shading provided by an accurate DTM. The mean peak to the west of the centre of the image is Knocklayd $(514 \mathrm{~m})$. The superficial deposits (1:250k) largely comprise alluvium (yellow), glacial sand and gravels (pink), till/diamicton (pale blue) and peat (brown). Figure 8b shows the total count (i.e. obtained across the full energy spectrum) radiometric data. The colour scale is linear ranging from 55 cps (cold colours) to 3100 cps (warm colours) and shading is again provided by the DTM. The lowest range of values (55 to $300 \mathrm{cps}$ ) has been contoured in white.

In broad terms it can seen that the material properties of the superficial deposits are mapped by their radiometric response. In detail however, there are several differences particularly with regard to the alluvial deposits across the valley floor. These differences can be further investigated using both the individual radioelements and their ratios. Turning now to the peat response, previously referred to in relation to the estimation of carbon stocks, the attenuated total count response corresponds closely with the mapped peat deposits throughout the southeast of the area, but significant differences exist. These are exemplified by the halo of low values at high elevation on the hilltop. Intriguing partial associations such as these now form the basis for continuing projects developing the knowledge base of the near-surface across the whole of Northern Ireland.

\section{The Tellus Effect: the future}

Since the information is new and challenging, it will allow UK scientists to continue to develop ideas, test procedures and new science across a range of disciplines. Much of this will take place within GIS and Information Technology environments. A rather more straightforward example arises in the case of geophysical processing to detect concealed structure. Figure 9 shows the Tilt Derivative (TDR) which exploits gradients in the magnetic data. The technique is a recently established procedure. The magnetic data have first been reduced-to-pole and upward-continued to $500 \mathrm{~m}$. The TDR has a range of values from $-90^{\circ}$ to $+90^{\circ}$. The contours shown are $-45^{\circ}$ to $0^{\circ}$ (blue) and $0^{\circ}$ to $45^{\circ}$ (red). The zero crossings identify the edges of sources such as faults or boundaries between basement zones of different 
composition or magnetisation. To the west of the Antrim Plateau the image reveals, with a good degree of precision, some of the significant Caledonian terrane boundaries with northeast and north-northeast trends. The half-distance between the $-45^{\circ}$ and $45^{\circ}$ contours provides an estimate of the depth of the source (assuming a simple vertical contact). The new data will therefore assist with the definition of significant basement features which have remained controversial.

While the new magnetic data improve on previous versions, the conductivity data have revealed entirely new structures. New theoretical modeling was carried out to evaluate under what conditions the TDR transform could be applied to electromagnetic (EM) conductivity data (i.e. data obeying Faraday's, rather than Laplace's, equation). The results indicate that the EM field interactions with simple structures do not provide equivalent simple depth discrimination but that a mapping of the TDR between $0^{\circ}$ and $90^{\circ}$ allows the centre of conductive zones to be identified. In the EM case, source discrimination takes place within a focused volumetric footprint and the physics provides no long wavelength information. The TDR of the $3 \mathrm{kHz}$ conductivity data shown previously is presented in Figure 10 across a $14 \mathrm{x}$ $14 \mathrm{~km}$ area in the SUDL terrane (rectangle 4, Fig. 1$)$. The red contours $\left(45^{\circ}\right.$ to $\left.90^{\circ}\right)$ facilitate a clear representation of all the shallow and deep conductive zones identified by their gradients within the data set. The sinuous, quasi-linear conductive zones crossing the whole area have been interpreted as the Moffat Shale Group (largely concealed) which, as pelagic muds on the floor of the former Iapetus Ocean, formed a series of near-vertical decollment surfaces during the formation of the accretionary complex. The SUDL terrane has now been the subject of a significant reappraisal of the detail of its construction during continental closure.

Such new procedures have enabled some key developments in understanding and reinterpreting existing geological knowledge. Our expectation is that the Tellus baseline data will continue to provide a significant testbed for the development of both large and small new science initiatives for many years to come.

\section{Economy and environment}

Tellus, financed by the Department of Enterprise, Trade and Investment of Northern Ireland, was intended primarily to support economic development by encouraging natural resources exploration and by providing environmental baseline data. Since the results were released in October 2007, the area of land licensed for prospecting has increased from 15\% to 70\%, with entailed investment commitments of $£ 15$ million. Mining companies are focusing particularly on following up precious metal anomalies revealed by the geochemical surveys. As much of Northern Ireland is covered with a glacial overburden and peat, the high resolution airborne geophysical data greatly contributes to interpreting associated concealed bedrock structures.

This economic effect of the project also prompted renewed interest in the geothermal potential of Northern Ireland, where some of the highest borehole temperatures in Ireland have been recorded. Magnetotelluric and gravity surveys have just been completed over the prospective Lough Neagh basin. And to the northeast, three companies have licensed areas in the search for potential sites for the storage of gas in Permian salt beds, where Tellus data have been used to aid structural interpretation.

Tellus has sparked several environmental research programmes and the data have been widely taken up in fields including peat mapping and soil carbon assessment, contaminated land assessment, geostatistics and groundwater flow modelling. Environmental outputs employing these data include a new radon risk assessment for Northern Ireland and a new map of anthropogenic caesium fall-out (mostly from the Chernobyl accident). Research continues into possible correlations between radioactivity, toxic element distribution and the 
distribution of disease. A notable Tellus effect has therefore been a broadening of the scope of geoscience research into new fields and a raising of awareness of the wider value of earth science data in general.

Tellus has been the first project to obtain modern, cohesive, multi-parameter geophysical baseline data across many of the UK geological and soil formations. It promotes initiatives in natural resource development, provides key environmental baseline data, underpins new research in various fields and delivers on several objectives of government policy and innovation strategy.

\section{Acknowledgements}

Our grateful thanks go to the large number of people that have been involved in the Tellus Project which was funded by DETI and by the Building Sustainable Prosperity scheme of the Rural Development Programme (Department of Agriculture and Rural Development of Northern Ireland). This report is published with the permission of the Executive Director, British Geological Survey (NERC).

\section{Figure Captions}

Figure 1. Simplified geological map of Northern Ireland showing the outline of the aerogeophysical survey and the eight survey blocks $(2005,2006)$. The numbered rectangles are referred to in the text. Coordinates are Irish National Grid.

Figure 2. Comparison of existing (a) and new (b) magnetic data across a 10 x $20 \mathrm{~km}$ area (rectangle 1, Fig. 1). Fault lines at 1:625k are shown for spatial reference. Equal-area colour plots.

Figure 3. Pseudo-gravity transform applied to magnetic total field intensity data. Equal-area colour image.

Figure 4. Ternary colour image of radiometric data $($ Red $=$ Potassium $=$ POT, Green $=$ Thorium=THO and Blue=Uranium=URA).

Figure 5 . Conductivity obtained at $3 \mathrm{kHz}$ shown using a linear colour scale and with shaded relief from NW.

Figure 6. Data across a 4 x 4 km area (rectangle 2, Fig. 1). (a) $3 \mathrm{kHz}$ conductivity with overlay of topographic map. Two power-lines (PL) are indicated. (b) magnetic total intensity shown as an equal-area colour image.

Figure 7. Subsurface conductivity model (values $>60 \mathrm{mS} / \mathrm{m}$ ) obtained across the $1 \mathrm{x} 1 \mathrm{~km}$ area shown in Fig. 6. Perspective 3D view with transparent photographic surface image. Vertical scale $(30 \mathrm{~m})$ is exaggerated.

Figure 8. Data across a 10 x $10 \mathrm{~km}$ area (rectangle 3, Fig.1). (a) superficial deposits (1:250k): alluvium (yellow), glacial sand and gravels (pink), till/diamicton (pale blue) and peat (brown). Shading (from NW) provided by a DTM. (b) Total count radiometric data with shading provided by a DTM. The lowest range of values (55 to $300 \mathrm{cps}$ ) have been contoured in white. 
Figure 9. Tilt derivative (TDR) of total magnetic field intensity. The magnetic data have first been reduced-to-pole and upward-continued to $500 \mathrm{~m}$. The contours shown are $-45^{\circ}$ to $0^{\circ}$ (blue) and $0^{\circ}$ to $45^{\circ}$ (red).

Figure 10. Tilt derivative (TDR) of $3 \mathrm{kHz}$ conductivity data across a 14 x $14 \mathrm{~km}$ area (rectangle 4, Fig. 1) centred on the town of Newtownhamilton. The TDR response obtained follows upward-continuation $(100 \mathrm{~m})$ of the conductivity data across the area. Only positive values have been contoured ( 0 to $45^{\circ}$ in blue, $45^{\circ}$ to $90^{\circ}$ in red). The TDR response is overlain on a 1:250k road map with the location of five townships denoted by solid black symbols. The ellipse indicates the response of a power-line (PL) route. 


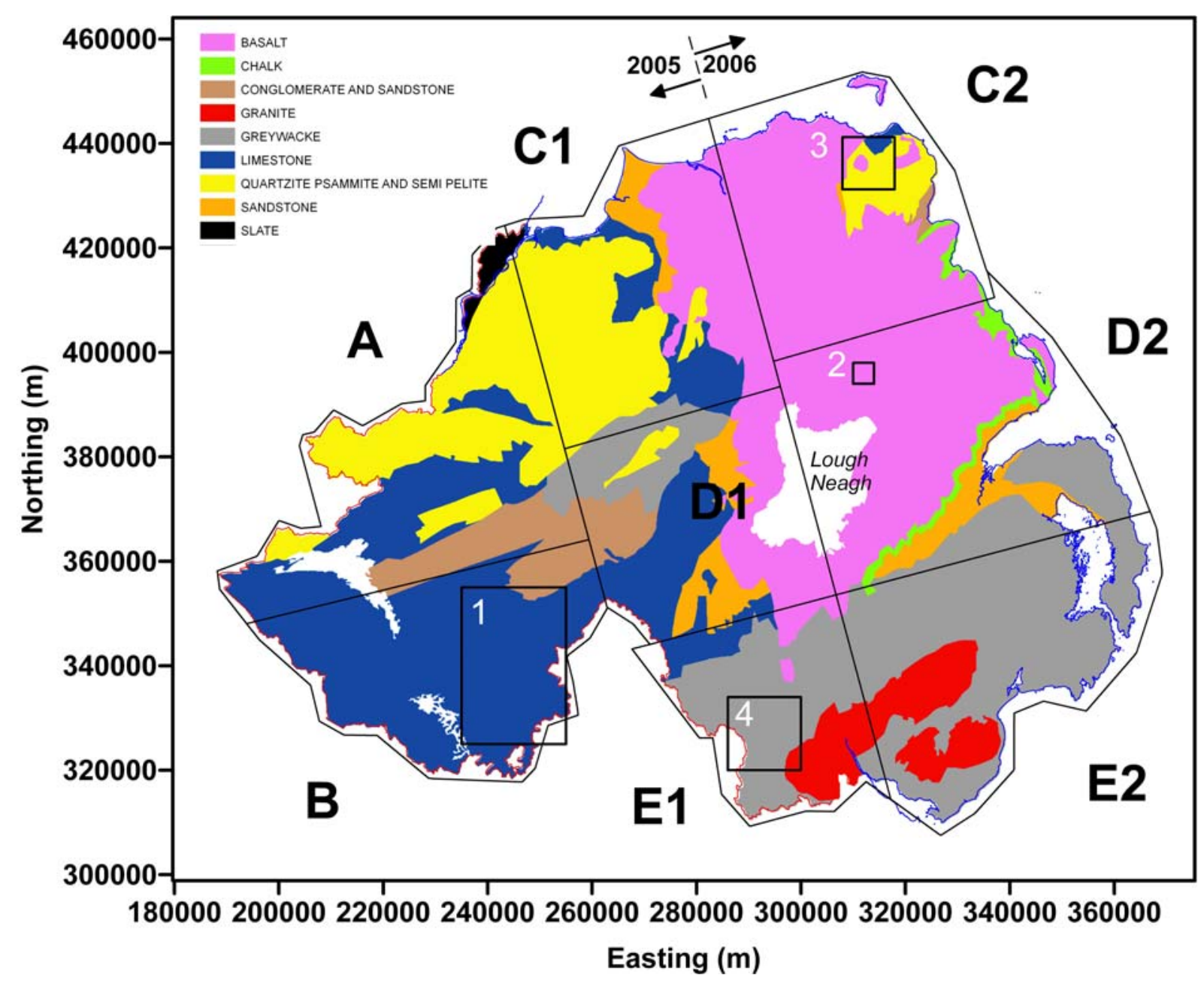

Figure 1. Simplified geological map of Northern Ireland showing the outline of the aerogeophysical survey and the eight survey blocks $(2005,2006)$. The numbered rectangles are referred to in the text. Coordinates are Irish National Grid. 


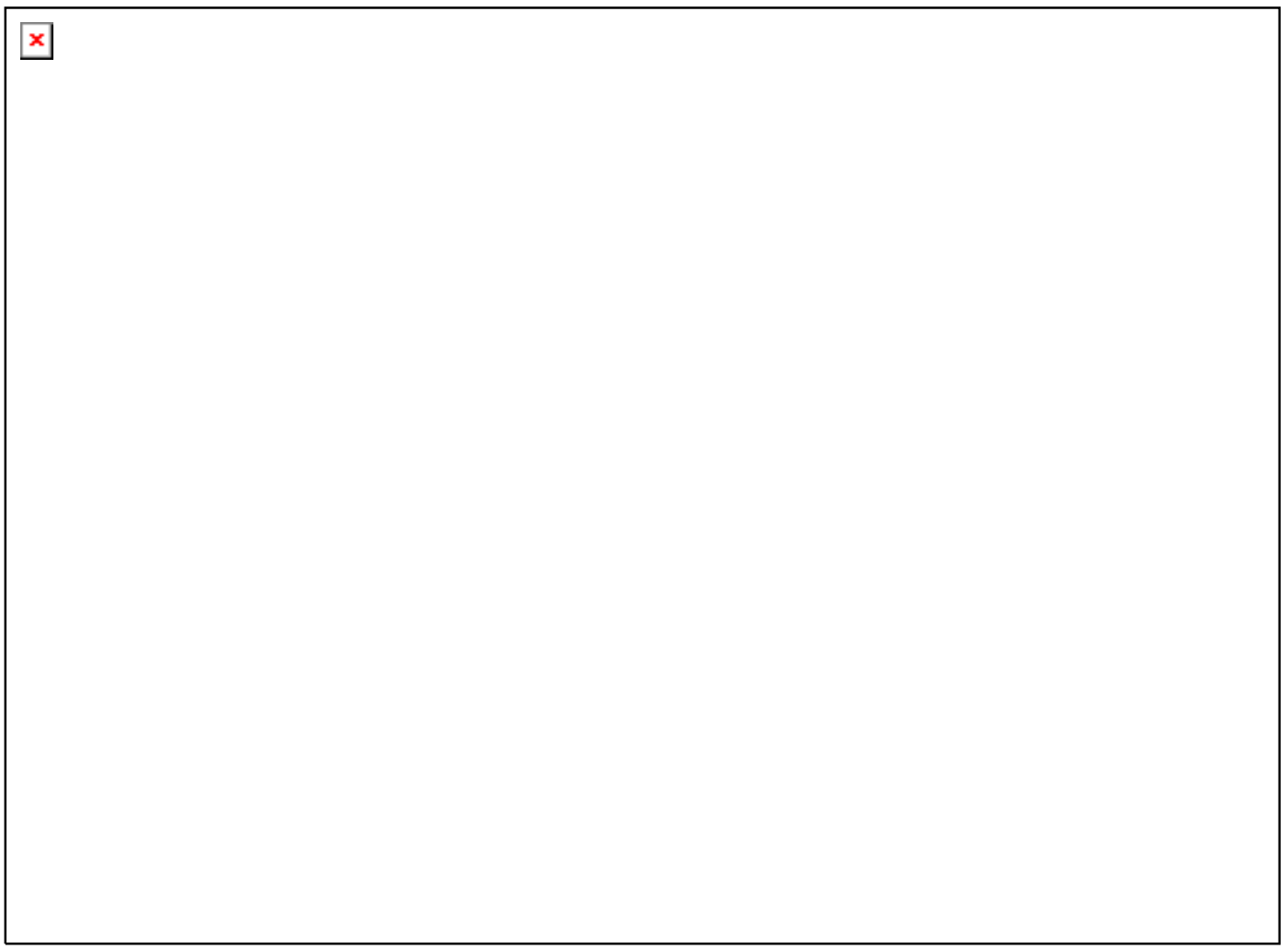

Figure 2. Comparison of existing (a) and new (b) magnetic data across a 10 x $20 \mathrm{~km}$ area (rectangle 1, Fig. 1). Fault lines at 1:625k are shown for spatial reference. Equal-area colour plots. 


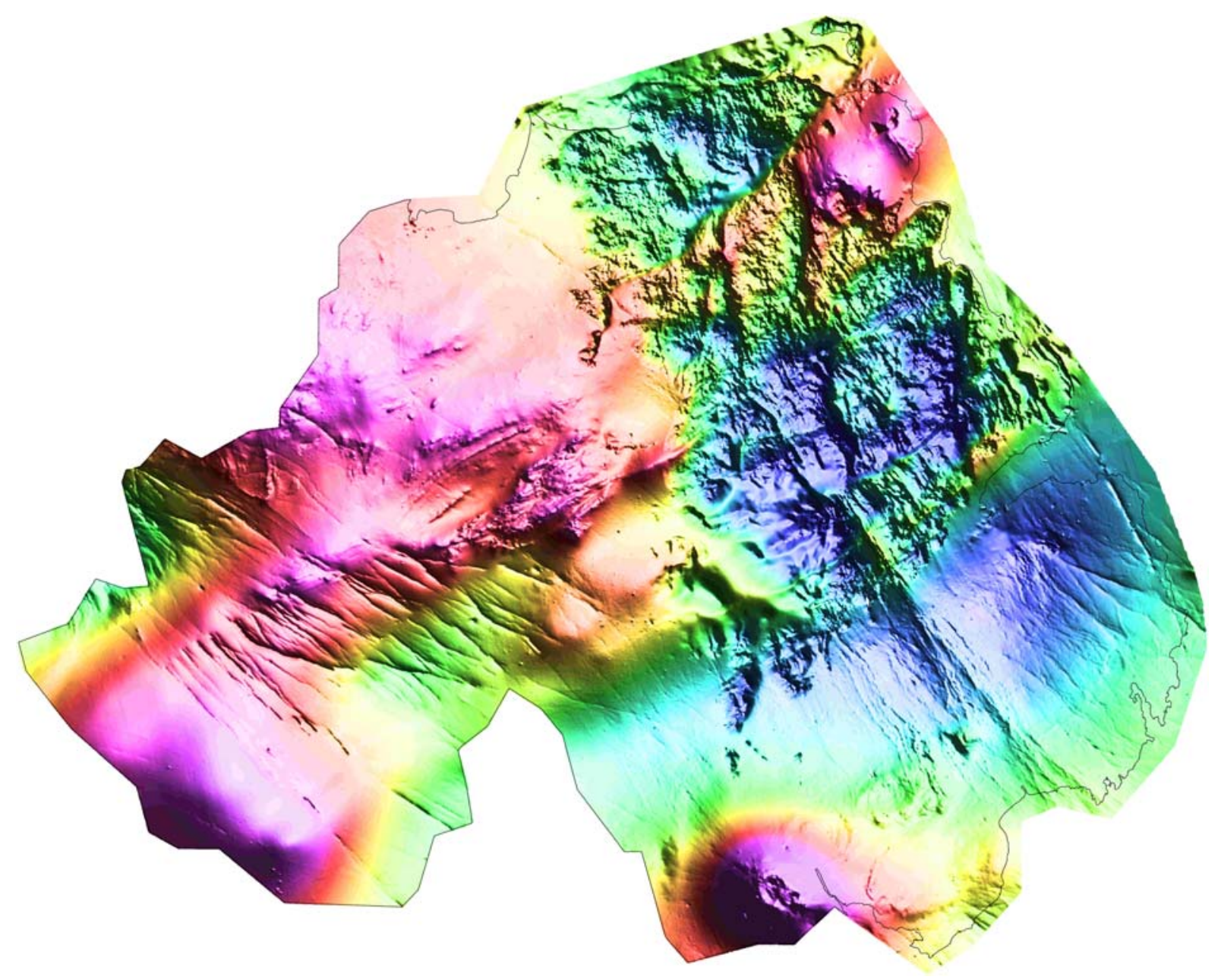

Figure 3. Pseudo-gravity transform applied to magnetic total field intensity data. Equal-area colour image. 


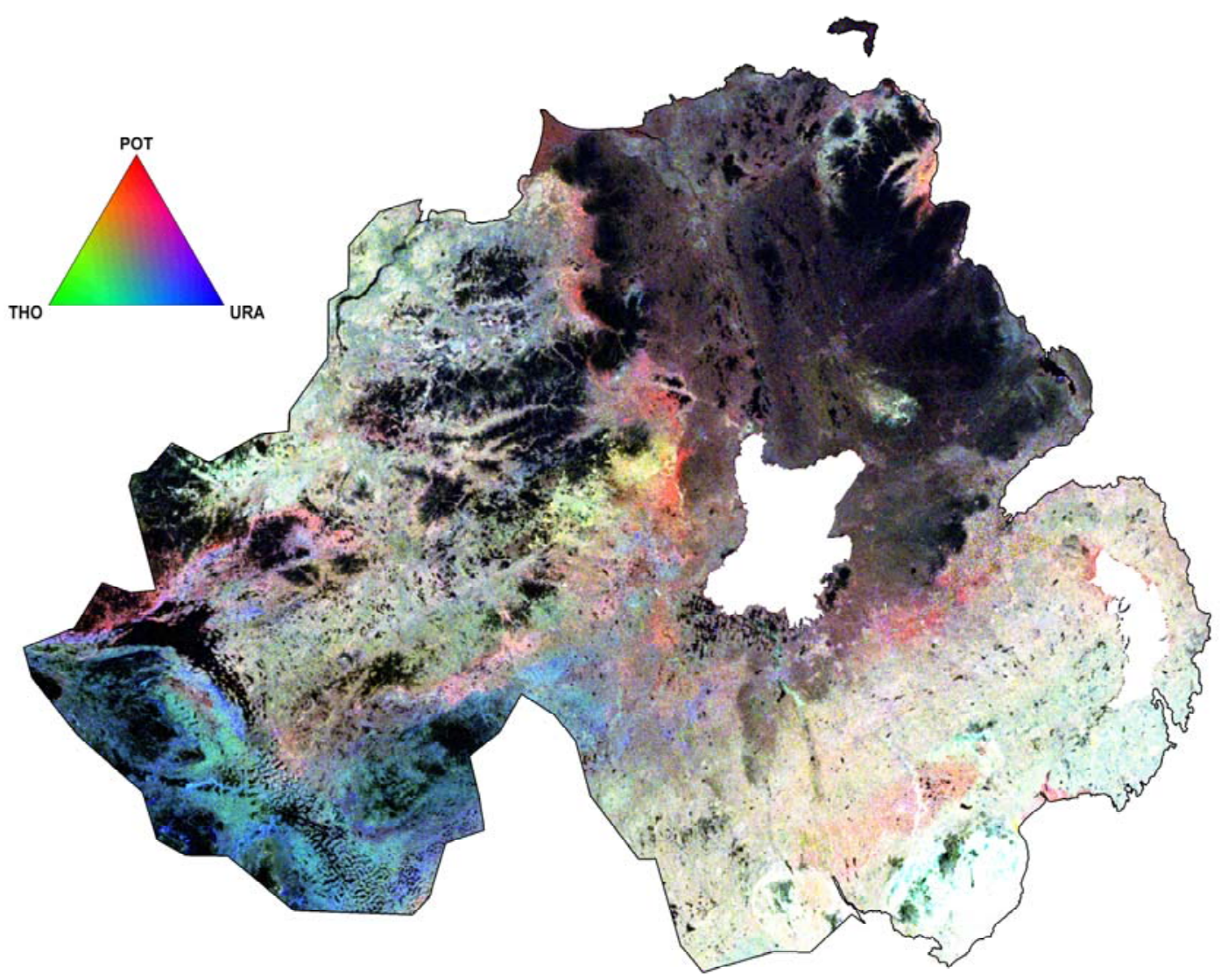

Figure 4. Ternary colour image of radiometric data $($ Red $=$ Potassium $=\mathrm{POT}$, Green $=$ Thorium=THO and Blue=Uranium=URA). 


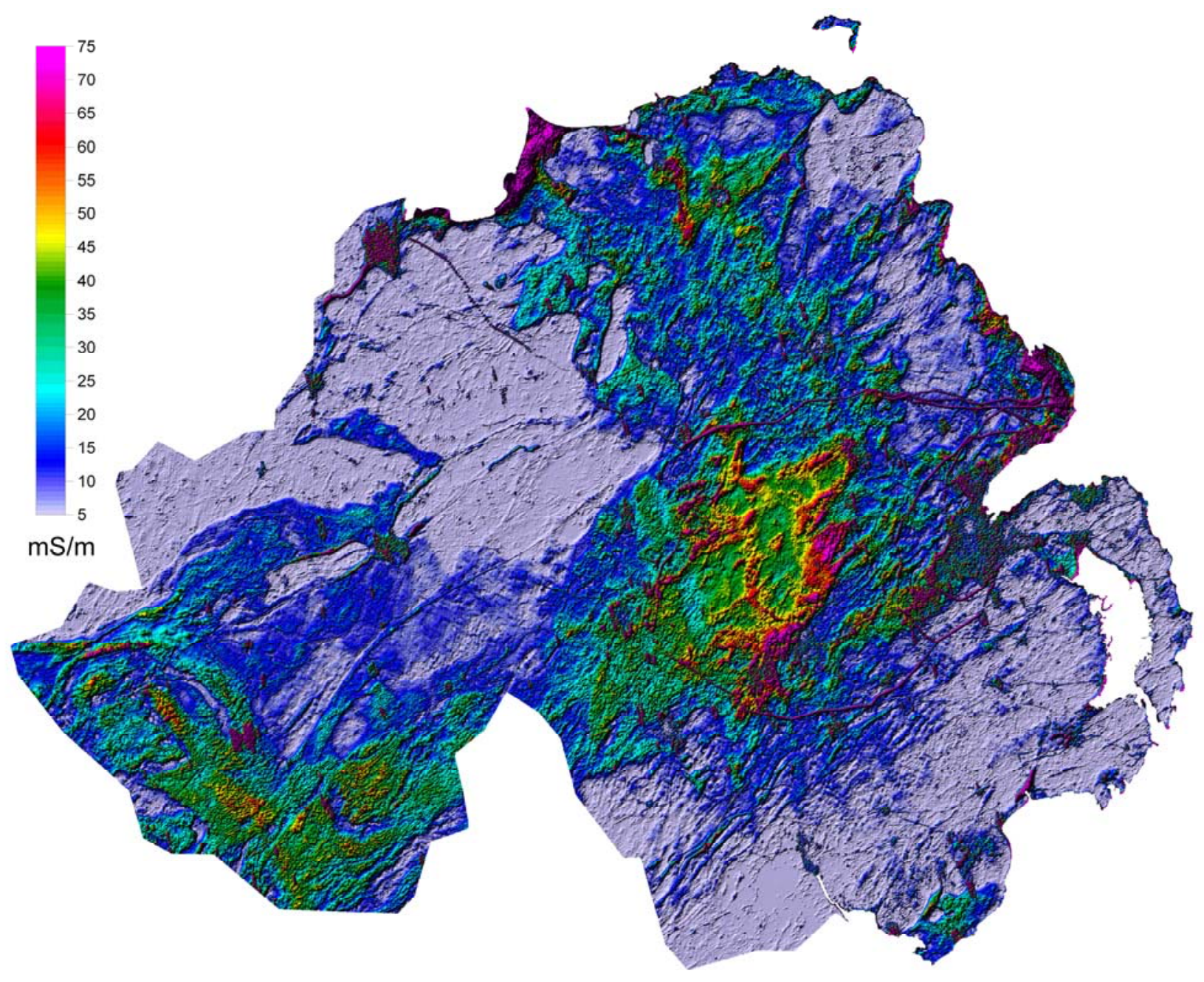

Figure 5 . Conductivity obtained at $3 \mathrm{kHz}$ shown using a linear colour scale and with shaded relief from NW. 

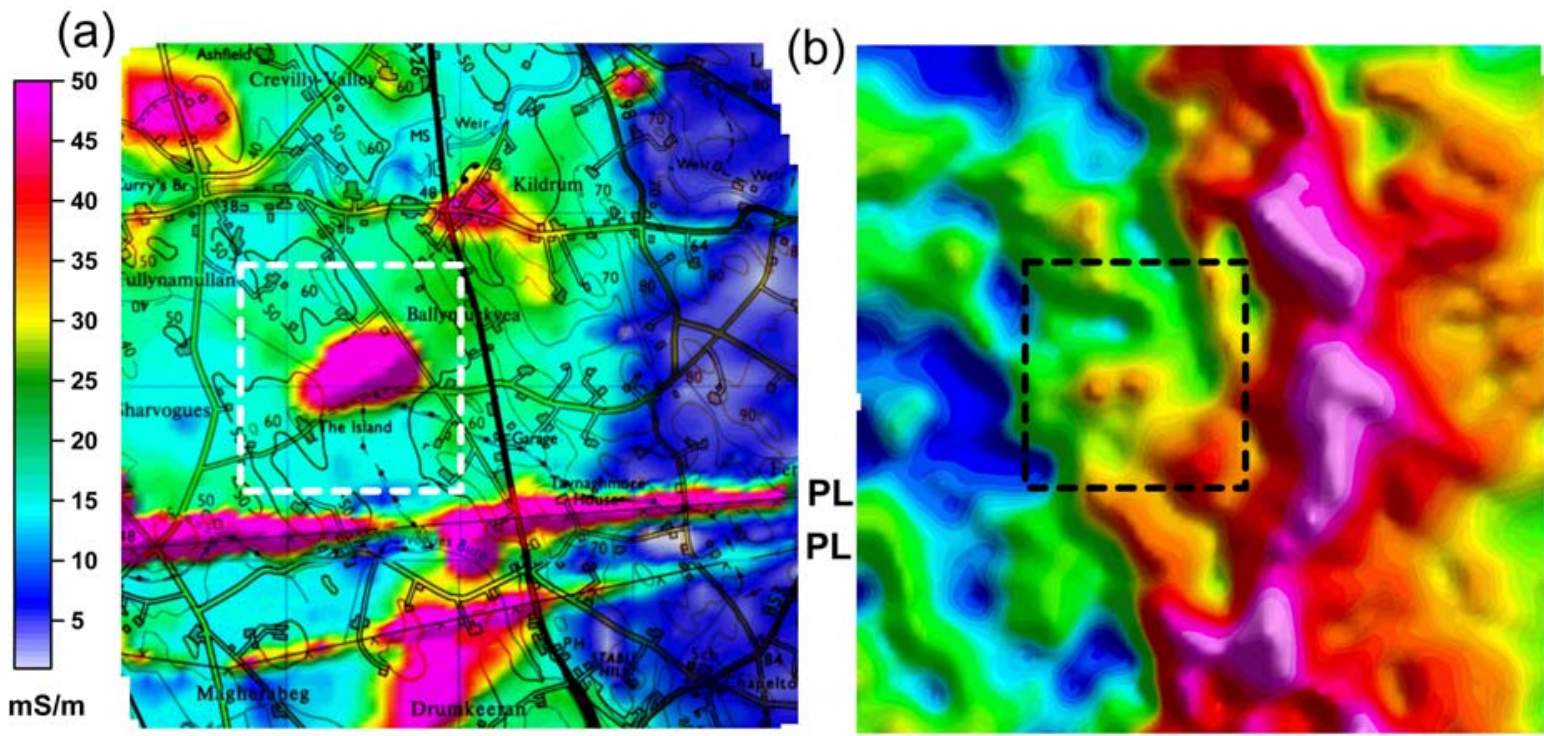

Figure 6. Data across a 4 x 4 km area (rectangle 2, Fig. 1). (a) $3 \mathrm{kHz}$ conductivity with overlay of topographic map. Two power-lines (PL) are indicated. (b) magnetic total intensity shown as an equal-area colour image. 


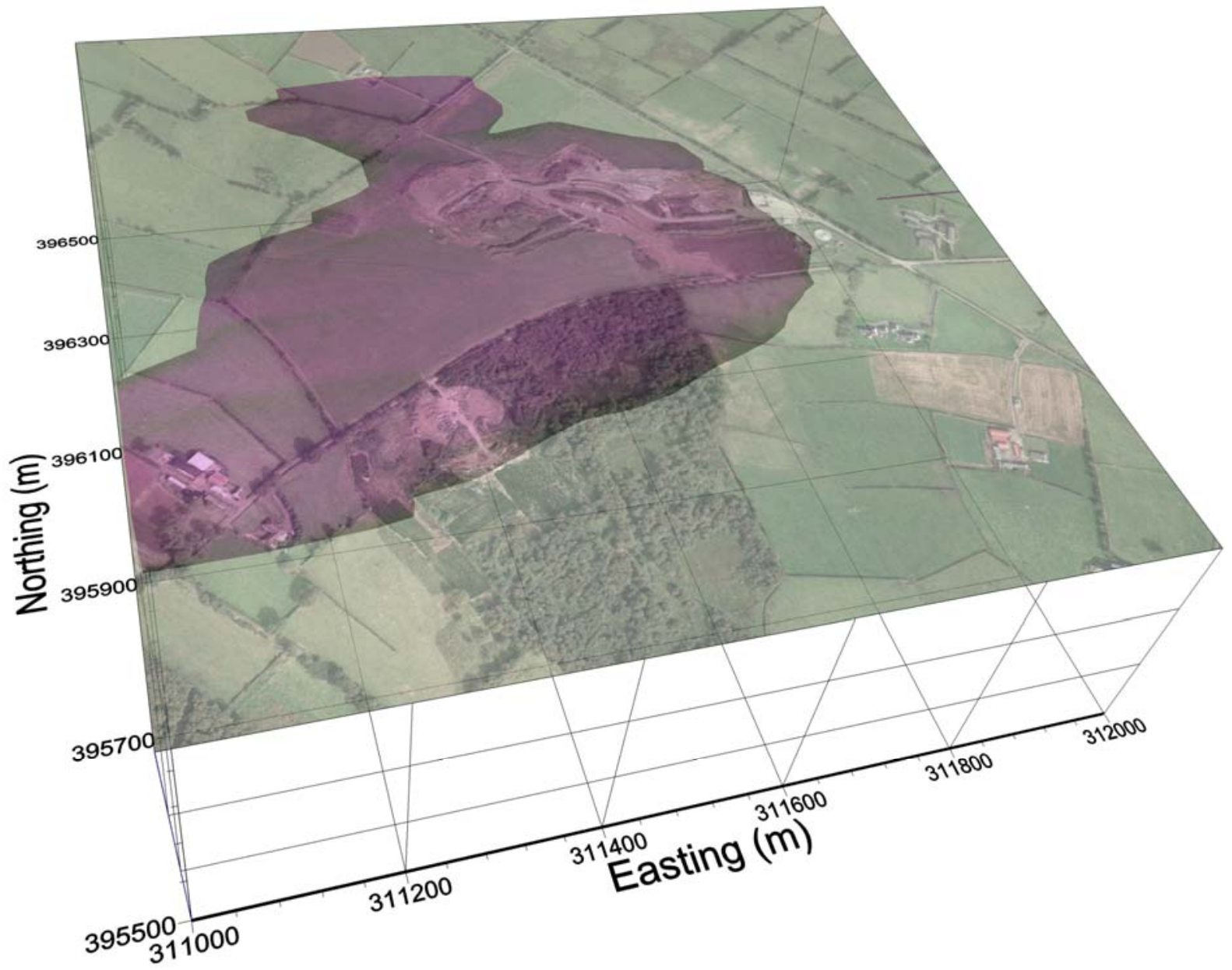

Figure 7. Subsurface conductivity model (values $>60 \mathrm{mS} / \mathrm{m}$ ) obtained across the $1 \mathrm{x} 1 \mathrm{~km}$ area shown in Fig. 6. Perspective 3D view with transparent photographic surface image. Vertical scale $(30 \mathrm{~m})$ is exaggerated. 

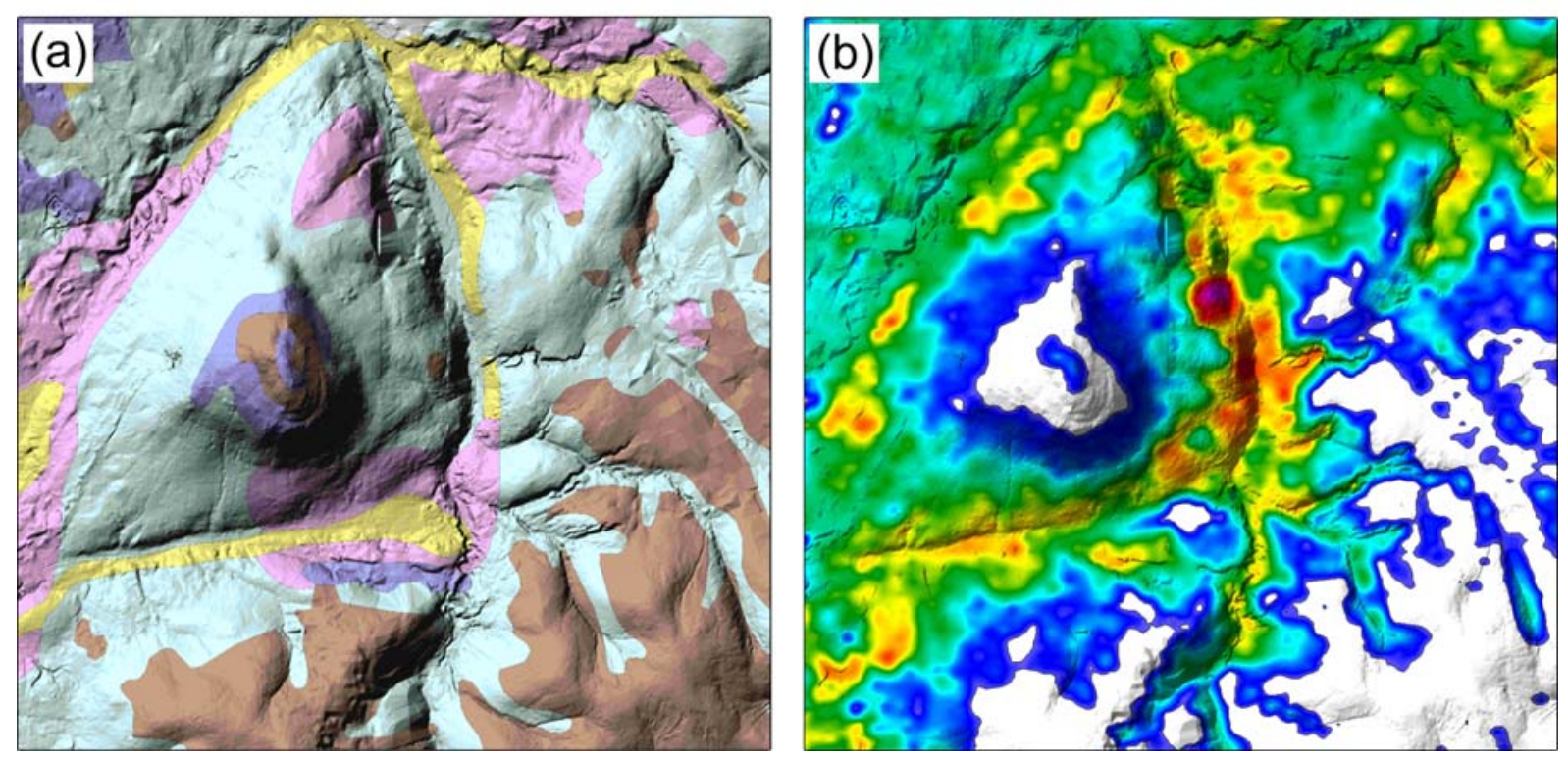

Figure 8. Data across a 10 x $10 \mathrm{~km}$ area (rectangle 3, Fig.1). (a) superficial deposits (1:250k): alluvium (yellow), glacial sand and gravels (pink), till/diamicton (pale blue) and peat (brown). Shading (from NW) provided by a DTM. (b) Total count radiometric data with shading provided by a DTM. The lowest range of values (55 to $300 \mathrm{cps}$ ) have been contoured in white. 


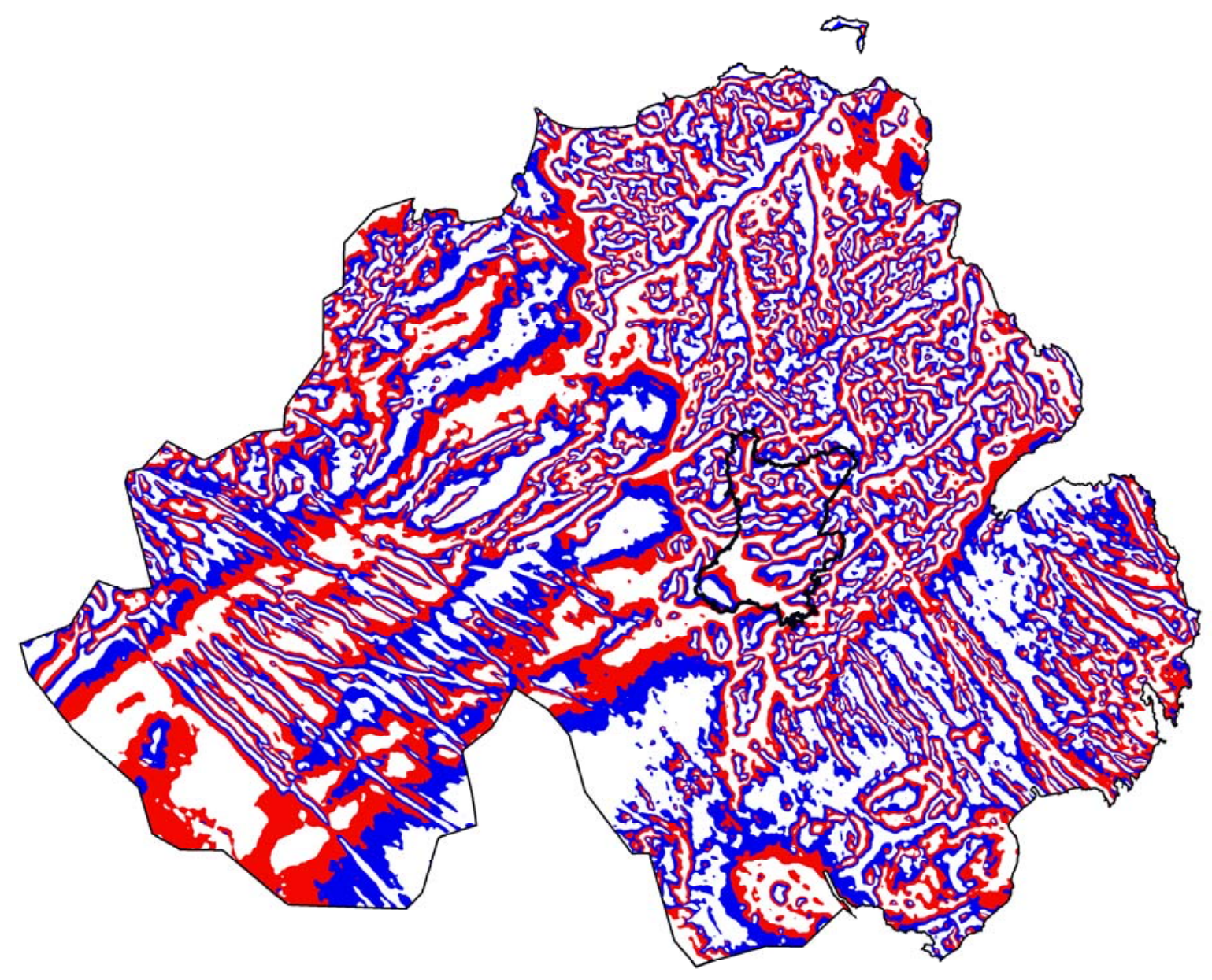

Figure 9. Tilt derivative (TDR) of total magnetic field intensity. The magnetic data have first been reduced-to-pole and upward-continued to $500 \mathrm{~m}$. The contours shown are $-45^{\circ}$ to $0^{\circ}$ (blue) and $0^{\circ}$ to $45^{\circ}$ (red). 


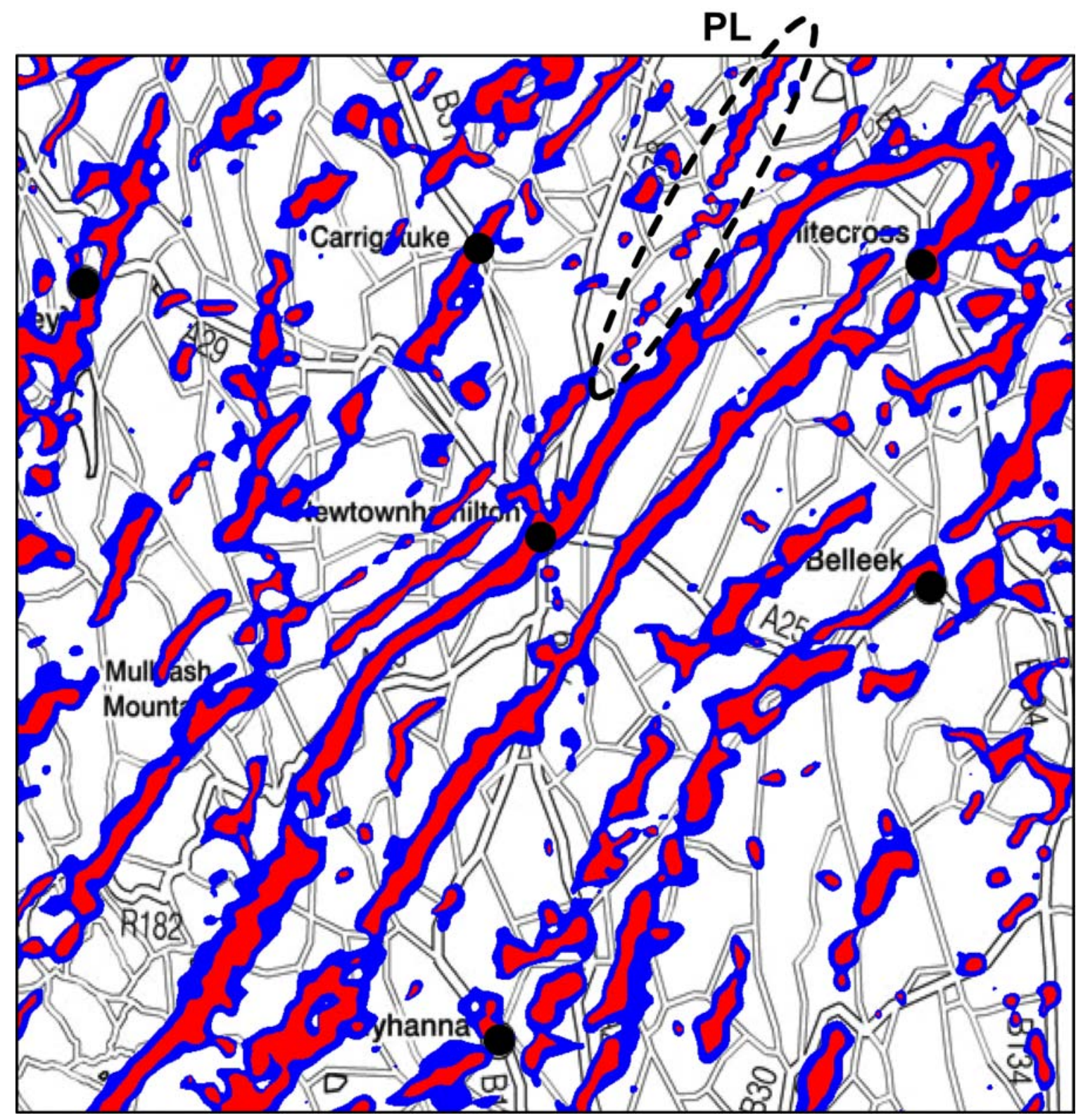

Figure 10. Tilt derivative (TDR) of $3 \mathrm{kHz}$ conductivity data across a $14 \mathrm{x} 14 \mathrm{~km}$ area (rectangle 4, Fig. 1) centred on the town of Newtownhamilton. The TDR response obtained follows upward-continuation $(100 \mathrm{~m})$ of the conductivity data across the area. Only positive values have been contoured ( 0 to $45^{\circ}$ in blue, $45^{\circ}$ to $90^{\circ}$ in red). The TDR response is overlain on a 1:250k road map with the location of five townships denoted by solid black symbols. The ellipse indicates the response of a power-line (PL) route. 